\title{
Nicotinamide N-Methyltransferase
}

National Cancer Institute

\section{Source}

National Cancer Institute. Nicotinamide N-Methyltransferase. NCI Thesaurus. Code C104568.

Nicotinamide N-methyltransferase (264 aa, $\sim 30 \mathrm{kDa}$ ) is encoded by the human NNMT gene. This protein is involved in the detoxification of xenobiotic compounds. 